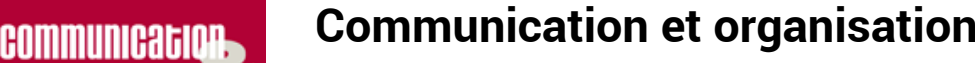

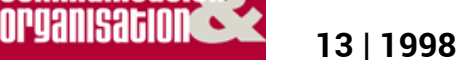

\section{Management par projet et logiques}

communicationnelles

\section{Avant-propos}

\section{Hugues Hotier}

\section{(2) OpenEdition}

\section{Journals}

Édition électronique

URL : http://journals.openedition.org/communicationorganisation/2016

DOI : 10.4000/communicationorganisation.2016

ISSN : 1775-3546

Éditeur

Presses universitaires de Bordeaux

Édition imprimée

Date de publication : 1 mai 1998

ISSN : 1168-5549

\section{Référence électronique}

Hugues Hotier, « Avant-propos », Communication et organisation [En ligne], 13 | 1998, mis en ligne le 26 mars 2012, consulté le 21 septembre 2020. URL : http://journals.openedition.org/

communicationorganisation/2016 ; DOI : https://doi.org/10.4000/communicationorganisation.2016

Ce document a été généré automatiquement le 21 septembre 2020.

(C) Presses universitaires de Bordeaux 


\title{
Avant-propos
}

\author{
Hugues Hotier
}

1 «Ce n'est pas sans une certaine émotion... » Ainsi commencent nombre de discours officiels. Au point que cette formule est reprise par les humoristes lorsqu'ils veulent parodier les hommes politiques. On pourrait lui adjoindre «En cette fin de siècle, à l'aube du troisième millénaire" et le catalogue des poncifs serait ainsi bien commencé... Soit. Je veux bien renoncer à cette seconde platitude mais je requiers votre indulgence si j'exprime ici mon émotion en introduisant ce treizième numéro de Communication \& Organisation.

2 Je suis sûr que si je feuilletais les numéros précédents, j'y trouverais d'autres traces de cette émotion que j'évoque. Il est vrai que chaque numéro est une aventure, et chaque parution une joie nouvelle, pour nous qui travaillons comme des artisans. Oserai-je rapporter les affres de Gino Gramaccia, qui a coordonné le dossier consacré à Management par projet et logiques communicationnelles ${ }^{1}$ ? Les articles qui n'arrivent pas à temps, les auteurs qui ne sont pas joignables, l'imprimeur qui menace de ne pas sortir à la date prévue si la copie ne lui est pas remise quasi immédiatement, la responsable des abonnements qui fait remarquer que les revues qui sortent en retard ne sont pas recensées... il y a là de quoi stresser le plus calme des universitaires. Et puis voilà que, miraculeusement, tout est prêt. Et, mieux encore, voilà qu'on envisage de rattraper le retard chronique qui altère notre rythme de parution. L'avez-vous remarqué, ce numéro 13, daté « $1^{\mathrm{er}}$ semestre 1998 » est sorti en juin 1998. Au premier semestre. À la date prévue!

3 Je n'ignore pas que, directeur de la publication, je me devrais d'attirer votre attention sur la qualité des articles de ce numéro, sur la notoriété ou la nouveauté de leurs auteurs, sur l'originalité de notre apport. À quoi bon ? N'appartient-il pas à nos lecteurs de participer à la construction du sens final ? Nous ne pouvons qu'espérer, qu'attendre et voir. En revanche, ce dont je suis certain c'est que notre petit groupe fait beaucoup pour leur satisfaction. C'est de cela que j'aimerais témoigner. J'aimerais dire l'engagement des membres du comité éditorial et de nos correspondants. J'aimerais encore remercier les membres du comité de lecture qui, répartis dans l'espace francophone, accordent beaucoup de soin et d'intelligence à la correction des articles, 
et beaucoup de tact aussi lorsqu'il s'agit de ne pas blesser l'amour-propre d'un auteur. Et puis, j'aimerais dire combien nous sommes conscients de la chance que nous avons d'être secondés par notre équipe administrative. Marie Navarro gère les abonnements et veille à ce que les librairies qui nous diffusent soient toujours approvisionnées. Fabienne Arcos assure le secrétariat de la publication. C'est elle qui, entre autres tâches délicates, relance les auteurs retardataires et les poursuit jusqu'à leur faire rendre article de crainte de devoir rendre gorge. Marie et Fabienne sont des femmes de qualité, efficaces et compétentes. Il fallait bien finir par l'écrire. Voilà qui est fait. Qu'on veuille bien me pardonner s'il m'arrive un jour de le répéter mais il y a tant de gens qui se plaignent d'être mal secondés que je sens l'impérieux besoin de clamer la chance que nous avons de l'être si bien.

Et puisque je suis dans une veine optimiste, je voudrais encore dire notre bonheur de voir s'élargir le cercle de nos lecteurs. Nous ne sommes pas peu fiers lorsque la célèbre librairie Tekhné nous demande un réassortiment parce que tous les numéros en magasin sont épuisés. Et quel contentement de constater la fidélité de nos abonnés. Puis-je encore, sans me plaindre le moins du monde, confesser que notre équilibre financier n'est rendu possible que par les recherches sur contrat qui sont menées au sein du GREC/O, le groupe de recherche en communication des organisations, qui édite notre revue. Communication \& Organisation s'autofinance entièrement et ne bénéficie d'aucune subvention pour le moment. Pour le moment... Je ne me rends pas très bien compte de ce qui me pousse à insister sur cette réserve. Peut-être l'espoir...

Maintenant que nous avons levé un peu le voile sur les conditions de production de notre revue, nous espérons que vous voudrez bien nous pardonner ses imperfections. C'est vrai que les fautes que nous pourchassons avec ardeur et condamnons avec rigueur semblent parfois obtenir un sursis de l'imprimeur qui les maintient bien en place. C'est vrai qu'on trouve des coquilles et des erreurs typographiques dans Communication \& Organisation. Ce n'est pas normal même si c'est devenu le lot de beaucoup de revues scientifiques et nous le déplorons. Mais nous osons espérer que vous nous pardonnerez désormais un peu plus facilement.

Un dernier mot pour remercier ceux d'entre vous qui nous ont témoigné leur satisfaction à propos du volumineux $\mathrm{N}^{\circ} 12$. Les 430 pages consacrées à «Induction et communication ", complétées par les Textes préparatoires rédigés par les membres du GREC/O constituent une somme appréciable, un véritable point de la question. Ces deux volumes sont toujours disponibles et peuvent être acquis ensemble ou séparément. Voilà, rien ne manque à cet éditorial. Pas même la pub!

\section{NOTES}

1. Les connaisseurs n'ont certainement pas oublié les délirants discours politiques que Pierre Dac improvisait périodiquement dans Signé Furax, le célèbre feuilleton des années 50. 


\section{AUTEUR}

HUGUES HOTIER

Université Michel de Montaigne-Bordeaux 3 